\title{
Intercalation of Apocarotenoids from Annatto (Bixa orellana L.) into Layered Double Hydroxides
}

\author{
Gustavo F. Perotti, ${ }^{\oplus a, b}$ Felipe F. Silva, ${ }^{a}$ Ricardo A. A. de Couto, ${ }^{\circledR a}$ Filipe C. D. A. Lima, ${ }^{\oplus c}$ \\ Helena M. Petrilli, ${ }^{\oplus d}$ Fabrice Leroux, ${ }^{\oplus e}$ Ana M. C. Ferreira ${ }^{\circledR a}$ and Vera R. L. Constantino ${ }^{\circledR * a}$ \\ ${ }^{a}$ Departamento de Química Fundamental, Instituto de Química, Universidade de São Paulo (USP), \\ Av. Prof Lineu Prestes, 748, 05508-000 São Paulo-SP, Brazil \\ ${ }^{b}$ Instituto de Ciências Exatas e Tecnologia, Universidade Federal do Amazonas (UFAM), \\ R. Nossa Senhora do Rosário, 3863, 69103-128 Itacoatiara-AM, Brazil \\ 'Instituto Federal de Educação, Ciência e Tecnologia de São Paulo (IFSP), Campus Matão, \\ Av. Stefano D'avassi, 625, 15991-502 Matão-SP, Brazil \\ ${ }^{d}$ Departamento de Física dos Materiais e Mecânica, Instituto de Física, \\ Universidade de São Paulo (USP), Rua do Matão, 1371, 05508-090 São Paulo-SP, Brazil \\ eInstitut de Chimie de Clermont-Ferrand ICCF, CNRS, Université Clermont Auvergne, \\ F-63000 Clermont-Ferrand, France
}

\begin{abstract}
Synthetic conditions were evaluated to intercalate norbixin into layered double hydroxides (LDH). Norbixin was isolated from a hydrosoluble commercial annatto extract. LDH samples comprising $\mathrm{M}^{2+} / \mathrm{Al}^{3+}(\mathrm{M}=\mathrm{Mg}, \mathrm{Zn})$ were synthesized by coprecipitation and characterized by $\mathrm{X}$-ray diffraction, thermal analysis coupled to mass spectrometry, vibrational spectroscopies, and solid-state ${ }^{13} \mathrm{C}$ nuclear magnetic resonance. Radical scavenging activity of LDH hybrids was monitored by electron paramagnetic resonance towards the stable radical DPPH (1,1-diphenyl2-picrylhydrazyl). LDH hosts presented more than $50 \mathrm{wt}$.\% of norbixin and d-spacing (003) values of about 2.5 or $3.0 \mathrm{~nm}$ depending of the cation LDH composition. Vibrational spectra assignment (supported by density functional theory calculations) confirmed the chemical integrity of norbixin after intercalation into LDH. The inorganic layers were found to enhance the thermal stability of norbixin upon intercalation. The free radical scavenging capacity of norbixin was retained when immobilized into LDH. Considering that zinc and magnesium-LDH matrices are biocompatible and that norbixin presents biological activity, the hybrid materials appear as promising systems for biomedical assessment.
\end{abstract}

Keywords: hydrotalcite, intercalation compounds, layered materials, norbixin, radical scavenging activity

\section{Introduction}

Bixin and norbixin are dyes belonging to the carotenoid class extracted from the red fruit seeds of annatto, a tropical plant (Bixa orellana L.) native of Central and South America (Figure 1a). Annatto extracts, bixin-based, are used worldwide as food additive in coloring milk drinks, butter, sweet sauces, chewing gum and fish, among other products. ${ }^{1,2}$ Furthermore the use as a natural coloring

*e-mail: vrlconst@iq.usp.br

Dedicated to Prof Henrique Eisi Toma on the occasion of his $70^{\text {th }}$ birthday. agent, annatto dyes show important properties for cosmetic and pharmacological applications such as antioxidant, anti-inflammatory, and anticarcinogenic..$^{2-7}$ Some studies have reported the norbixin activities, in particular, as antimutagenic, ${ }^{8}$ antimicrobial, ${ }^{9}$ hypolipidemic, ${ }^{10}$ and for oral macular degeneration treatment. ${ }^{11}$

Carotenoids are natural hydrocarbons (carotenes) containing eight isoprene units $\left[\mathrm{CH}_{2}=\mathrm{C}\left(\mathrm{CH}_{3}\right) \mathrm{CH}=\mathrm{CH}_{2}\right]$ (i.e., tetraterpenes), derived from lycopene ( $\Psi, \Psi$-carotene), which structure is shown in Figure $1 b .{ }^{12}$ Certain carotenoids contain cyclic end groups of nine carbon atoms, such as $\beta$-carotene. The carotenoids presenting oxygenated groups 
such as hydroxyl or epoxide are nominated xanthophylls, ${ }^{13}$ such as lutein (Figure 1c). In addition, carotenoids containing less than forty carbon atoms (due to the lack of fragments at one or both ends of the molecule) are known as apocarotenoids, as for instance bixin (Figure 1d), a monomethyl ester and the main dye in annatto. The double bonds in the polyene chain of carotenoids yield diverse geometrical and optical isomers. In the former kind of stereoisomerism, the molecules can present the all-trans (all- $E$ ) or $c i s(Z)$ isomers ${ }^{14}$ and, consequently, many sizes and shapes.

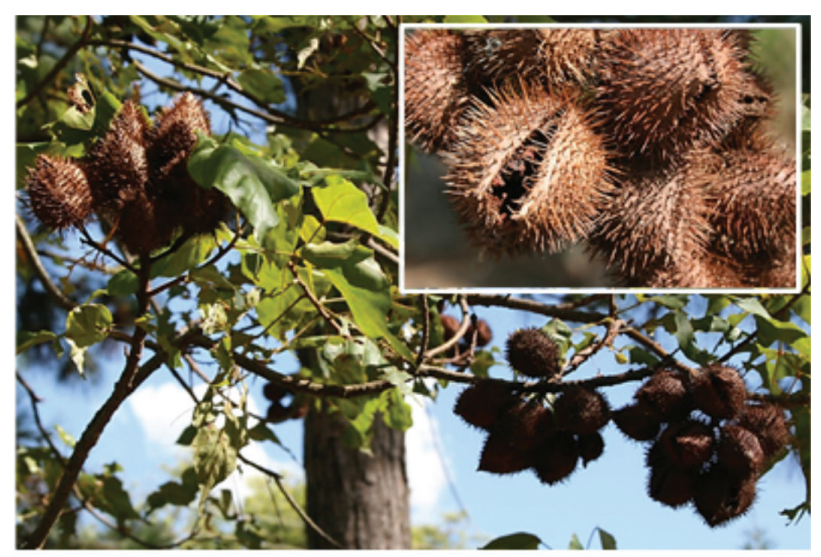

(a)

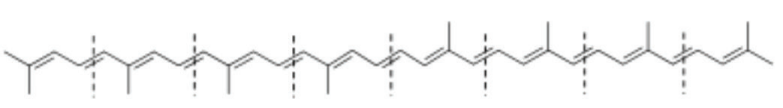

(b)

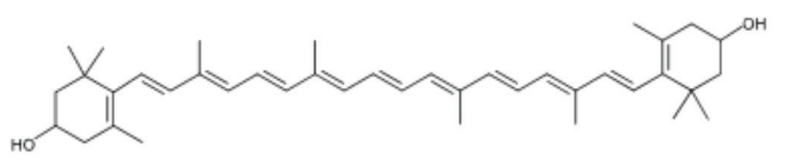

(c)

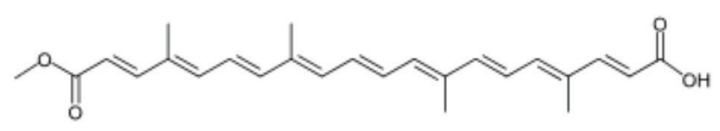

(d)

Figure 1. (a) Annatto tree (known as "urucuzeiro" in Brazil) and annatto fruit (known as "urucum"), a small capsule with soft spines containing the seeds/dyes; (b) carotenoid formed by isoprene (2-methylbuta-1,3-diene) units, indicated by broken lines; (c) carotenoid holding oxygenated end groups; (d) apocarotenoid bixin, a dye extracted from annatto seeds.

Norbixin is an apocarotenoid of formula $\mathrm{C}_{24} \mathrm{H}_{28} \mathrm{O}_{4}$ having carboxylic groups at the both ends of the polyene chain. This dye can be extracted from annatto seeds using an aqueous alkaline solution under heating or by the bixin hydrolysis of its ester group in alkaline solution. ${ }^{15}$ Carbon chains of carotenoids, such as bixin or norbixin, are rich in electrons and sensitive to oxidation process promoted, for example, by heat, light or peroxides..$^{15}$ One strategy to enhance the chemical stability of sensitive molecules is to protect them by encapsulation or confinement using hosts or carriers, increasing its shelf life or preventing its rapid degradation in the living organism. In this way, bixin and norbixin have been incorporated into cyclodextrins, ${ }^{16,17}$ or microencapsulated into gum arabic and maltodextrin, ${ }^{18,19}$ for instance.

Layered double hydroxides (LDH), two-dimensional (2-D) materials, can also be used as hosts or carriers since they are able to encapsulate species, by intercalation process, in their cavities located between the stacked layers. ${ }^{20}$ Review works ${ }^{21-23}$ have reported studies comprising the ability of LDH to protect bioactive species from thermal or in vivo degradation. The intercalation of species that present bioactive properties is also advantageous if bearing in mind that $\mathrm{LDH}$ structures possessing the hydrotalcite mineral composition $\left(\left[\mathrm{Mg}_{6} \mathrm{Al}_{2}(\mathrm{OH})_{16}\right] \mathrm{CO}_{3} \cdot 4 \mathrm{H}_{2} \mathrm{O}\right)$ are orally administrated as commercial antacid in quite a few brand names. ${ }^{24}$ Considering the positive electric charge of LDH layers and its general formula $\left[\mathrm{M}_{(1-x)}^{\mathrm{II}} \mathrm{M}^{\mathrm{III}}{ }_{\mathrm{x}}(\mathrm{OH})_{2}\right]\left(\mathrm{A}^{\mathrm{m}-}\right)_{\mathrm{x} / \mathrm{m}}$. $\mathrm{nH}_{2} \mathrm{O}\left(\mathrm{M}^{\mathrm{II}}\right.$ and $\mathrm{M}^{\mathrm{III}}$ are divalent and trivalent cations; $\mathrm{A}^{\mathrm{m}-}$ is an ion located in the interlayer region), anionic species can be intercalated and released by ion-exchange process and the loading capacity is guided by the amount of intralayer trivalent cation. While the majority of the drug delivery carriers shows a loading capacity lower than $10 \%$ (mass/ mass), ${ }^{25}$ LDHs have exhibited values as high as $40-60 \%$ when intercalated with some commercial drugs..$^{26-28}$

Considering antioxidant species, anionic derivatives of carnosine, ${ }^{29}$ gallic acid, ${ }^{29,30}$ caffeic acid, ${ }^{31}$ ferulic $^{32}$ and ascorbic acids ${ }^{32}$ were successfully intercalated into LDH layers and kept their radical scavenging properties. Beyond application in pharmaceutical and medicinal fields, the LDH-antioxidant systems have been evaluated as filler for polymer composites to enhance the chemical stability against (photo)oxidative degradation of carbon chain and also to improve the thermal and mechanical properties of the organic phase..$^{33,34}$

The aim of the present study was to assess synthetic conditions to intercalate norbixin, a natural dye and bioactive species, into LDH and investigate the radical scavenging activity of these hybrid materials. The norbixin was extracted from a commercial extract and characterized by high-performance liquid chromatography (HPLC) and spectroscopic techniques such as vibrational spectroscopy (infrared and Raman) and solid-state ${ }^{13} \mathrm{C}$ nuclear magnetic resonance (NMR). Synthesized LDH-Norbix materials were characterized by X-ray diffractometry, mass coupled thermogravimetric analyses (TGA-MS), vibrational and ${ }^{13} \mathrm{C}$ NMR spectroscopies, and chemical elemental analysis. The interpretation of vibrational spectroscopic data was supported by density functional theory (DFT) calculations 
of 9'-cis-norbixin. The antioxidant property of intercalated norbixin was evaluated by monitoring the reaction with DPPH (1,1-diphenyl-2-picrylhydrazyl) radical by electron paramagnetic resonance (EPR).

\section{Experimental}

Magnesium chloride hexahydrate $\left(\mathrm{MgCl}_{2} \cdot 6 \mathrm{H}_{2} \mathrm{O}\right.$, Merck, Darmstadt, Germany), aluminum chloride hexahydrate $\left(\mathrm{AlCl}_{3} \cdot 6 \mathrm{H}_{2} \mathrm{O}\right.$, Sigma-Aldrich, St. Louis, USA), zinc chloride ( $\mathrm{ZnCl}_{2}$, Merck, Darmstadt, Germany), sodium hydroxide (Merck, Darmstadt, Germany), hydrochloric acid solution (Labsynth, Diadema, Brazil), 1,1-diphenyl2-picrylhydrazyl (Sigma-Aldrich, St. Louis, USA), ethanol absolute (Merck, Darmstadt, Germany), and methanol (Labsynth, Diadema, Brazil) were used without further purification. All solutions were prepared with deionized water.

\section{Norbixin isolation from annatto extract}

About $200 \mathrm{~mL}$ of a commercial hydrosoluble annatto extract (A-260-WS, from Chr. Hansen Ind. e Com. Ltda., Valinhos, SP, Brazil) was filtered in a sintered funnel under reduced pressure and diluted to $800 \mathrm{~mL}$ by deionized water addition. The solution was filtered again under reduced pressure and $240 \mathrm{~mL}$ of $\mathrm{HCl} 0.5 \mathrm{~mol} \mathrm{~L}^{-1}$ solution was gently dropped in the filtrate under stirring. The deep colored precipitate was separated by centrifugation and washed with distilled water. The washing step was stopped when the test for chloride ions, by reaction with $0.5 \mathrm{~mol} \mathrm{~L}{ }^{-1} \mathrm{AgNO}_{3}$ solution, was negative. The precipitate was dried under reduced pressure in a desiccator with silica gel.

\section{Norbixin intercalation into LDH}

The synthesis of hybrid $\mathrm{Mg}_{2} \mathrm{Al}-\mathrm{LDH}$ material was conducted by coprecipitation method at constant $\mathrm{pH}$ value and under nitrogen gas, using $0.723 \mathrm{~g}$ of magnesium chloride hexahydrate, $0.430 \mathrm{~g}$ of aluminum chloride hexahydrate and $1.154 \mathrm{~g}$ of norbixin. The organic dye was dispersed in $100 \mathrm{~mL}$ of deionized water under a flow of $\mathrm{N}_{2}$ gas in a three-neck flask equipped with a magnetic stir bar and connected to two dropping funnels. A solution of metal cation salts $\left(\mathrm{Al}^{3+}+\mathrm{Mg}^{2+}=0.05 \mathrm{~mol} \mathrm{~L}^{-1}\right)$ was placed in one funnel and a $0.5 \mathrm{~mol} \mathrm{~L}^{-1} \mathrm{NaOH}$ solution in another funnel. Metal cations solution was added dropwise to the norbixin solution and the $\mathrm{pH}$ value kept at $9-10$ by the sodium hydroxide solution addition. After this step, the colored suspension was maintained under stirring and $\mathrm{N}_{2}$ gas atmosphere for 7 days at room temperature. The solid was separated by centrifugation, washed with distilled water up to observe a colorless supernatant, and dried under reduced pressure in a desiccator with silica gel. Samples were labelled as the simplified writing $\mathrm{M}^{\mathrm{II}}{ }_{\mathrm{R}} \mathrm{M}^{\mathrm{III}}$-Norbix ( $\mathrm{R}$ is the $\left[\mathrm{M}^{\mathrm{II}}\right] /\left[\mathrm{M}^{\mathrm{III}}\right]$ molar ratio). A similar synthetic procedure was used to obtain the $\mathrm{Zn}_{2}$ Al-Norbix material using $0.307 \mathrm{~g}$ of zinc chloride, $0.273 \mathrm{~g}$ of aluminum chloride hexahydrate and $0.502 \mathrm{~g}$ of norbixin; the $\mathrm{pH}$ value was kept at around 7 during the coprecipitation process.

\section{Radical scavenging assays}

Radical scavenging assays were performed recording the EPR spectra in a Bruker EMX instrument, operating at X-band $(9.62 \mathrm{GHz})$, using $10.11 \mathrm{~mW}$ power and $100 \mathrm{kHz}$ modulation frequency. Solutions were analyzed in quartz flat cells from Wilmad. Different volumes of norbixin ethanolic solution $\left(2.50 \mathrm{mmol} \mathrm{L}^{-1}\right)$ were added to a recently prepared DPPH ethanolic solution $\left(2.03 \mathrm{mmol} \mathrm{L}^{-1}\right)$, and the spectra of $200 \mu \mathrm{L}$ samples were subsequently recorded, using usually $4.48 \times 10^{2}$ gain and $1 \mathrm{G}$ of modulation amplitude. For the experiments with LDH-Norbix materials, $40 \mathrm{mg}$ of the powdered samples were mixed and stirred with $4 \mathrm{~mL}$ of a $1 \mathrm{mmol} \mathrm{L}{ }^{-1} \mathrm{DPPH}$ in ethanol solution, and the spectra of the supernatant solutions were registered immediately or after specified times.

\section{Characterization techniques}

Elemental chemical analysis $(\mathrm{C}, \mathrm{H}$ and $\mathrm{N})$ were conducted on a PerkinElmer 2400 analyzer at the Instituto de Química (Universidade de São Paulo-USP). Metals quantification were determined in duplicate by inductively coupled plasma (ICP) emission spectroscopy on a Spectro Analytical Instruments equipment at the Instituto de Química (Universidade de São Paulo-USP). HPLC analysis of isolated norbixin was carried out using a HPLC/UV-Vis Shimadzu LC-20 system equipped with a photodiode array detector, and a column Shim-pack ODS $(25 \mathrm{~cm})$. Norbixin was dissolved in an acetic acid $2 \% \mathrm{v} / \mathrm{v}$ ethanolic solution. The mobile phase consisted of solvent A (methanol) and solvent B (acetic acid 2\% v/v aqueous solution) delivered at $90 \% \mathrm{~A}: 10 \% \mathrm{~B}$. The flow rate was $1 \mathrm{~mL} \mathrm{~min}^{-1}$ and the column temperature was set at $30^{\circ} \mathrm{C}$. Photodiode array (PDA) detection was programmed to scan between 210 and $600 \mathrm{~nm}$. Norbixin solution was filtered through a $0.2 \mathrm{~mm}$ membrane filter prior to analysis. X-ray diffraction (XRD) patterns of powdered samples were recorded on a Rigaku diffractometer, model Miniflex, using $\mathrm{Cu} \mathrm{K \alpha}$ radiation (1.541 $\AA, 30 \mathrm{kV}$ and $15 \mathrm{~mA}$, scan step of $0.03^{\circ} \mathrm{s}^{-1}$ ) and Ni filter. TGA-MS were recorded 
on a Netzsch thermoanalyser model TGA/DSC 490 PC Luxx coupled to an Aëolos 403C mass spectrometer, using a heating rate of $10^{\circ} \mathrm{C} \mathrm{min}^{-1}$ and synthetic air flow

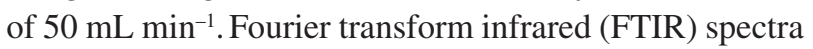
were recorded on a Bomem spectrophotometer, model MB-102, with a reflectance accessory; the samples were diluted in dried KBr. Fourier transform Raman (FT-Raman) spectra were recorded in a FT-Raman Bruker FRS-100/S spectrometer using $1064 \mathrm{~nm}$ exciting radiation (Nd:YAG laser Coherent Compass 1064-500N) and a Ge detector. Laser power has always been kept below $20 \mathrm{~mW}$ to avoid sample degradation. Solid state ${ }^{13} \mathrm{C}(\mathrm{I}=1 / 2)$ NMR spectra were recorded in a 300 Bruker spectrometer at $75.47 \mathrm{MHz}$ using magic angle spinning condition at $10 \mathrm{kHz}$ with a $4 \mathrm{~mm}$ diameter size zirconia rotor. ${ }^{13} \mathrm{C}$ spectra obtained by proton enhanced cross-polarization method $(\mathrm{CP}$, contact time of $1 \mathrm{~ms}$, recycling time of $5 \mathrm{~s}$ ) are referenced to the carbonyl of glycine calibrated at $176.03 \mathrm{ppm}$.

\section{Computational details}

The 9'-cis-norbixin molecule was designed using the Avogadro software ${ }^{35}$ and pre-optimized using molecular mechanics with the general Amber force field (GAFF). ${ }^{36}$ Quantum chemistry calculations were carried out using the density functional theory (DFT) in the Kohn-Sham scheme, using the Gaussian 09 computational package. ${ }^{37}$ The B3LYP ${ }^{38}$ exchange correlation functional and the Pople's basis set 6-311G(d,p) were employed. Within this setup, the geometry relaxation was done under vacuum conditions, reaching a global minimum of the potential energy surface. Afterwards, vibrational calculations for the isolated molecule were performed at $300 \mathrm{~K}$, the default software setup, and no negative frequencies were obtained. A 0.9614 shift correction was applied to the calculated wavenumbers, in the comparison with the experimental results, following the literature. ${ }^{39}$

\section{Results and Discussion}

The commercial annatto extract used in this study was an alkaline paste having norbixin in the deprotonated form besides other compounds from annatto seeds. The addition of $\mathrm{HCl}$ solution to the extract promoted the dye protonation and, consequently, precipitation of norbixin in aqueous media. The composition of the isolated colored solid was evaluated using HPLC and UV-Vis techniques. HPLC isocratic elution method adopted in this work for the dye analysis was described by Lancaster and Lawrence, ${ }^{40}$ which allowed chromatographic separation of norbixin isomers. According to HPLC data (Figure 2), a total of 8 peaks were detected; peak 7 was the most intense, followed by peaks 2 and 3. The UV-Vis spectra of peaks 2, 3 and 7 (shown as inset in Figure 2) revealed that the species related to the chromatographic peaks have mainly two bands in the 453-462 $\mathrm{nm}$ and 477-491 nm spectral range, which are attributed to isomers of norbixin. ${ }^{41,42}$ Since the main carotenoid present in annatto seeds is the isomer 9'-cis-bixin, alkali hydrolysis under mild temperature yields mostly the product 9'-cis-norbixin. ${ }^{15}$ Hence, peak 7 was associated to this isomer that presents bands at 438, 460 and $486 \mathrm{~nm}$ when analyzed by HPLC-PDA in methanol/acetic acid media, ${ }^{43}$ corroborating to the chromatographic peak assignment. However, chemical and/or thermal treatment employed to isolate norbixin and its isomers can also yield the linear trans-norbixin, which is thermodynamically more stable than cis isomer, although it is obtained extensively under optimized conditions..$^{15,43}$ The trans-norbixin exhibits two main bands at 465 and $493 \mathrm{~nm} ;{ }^{43}$ hence its presence was associated with the peak 2 in the chromatogram.

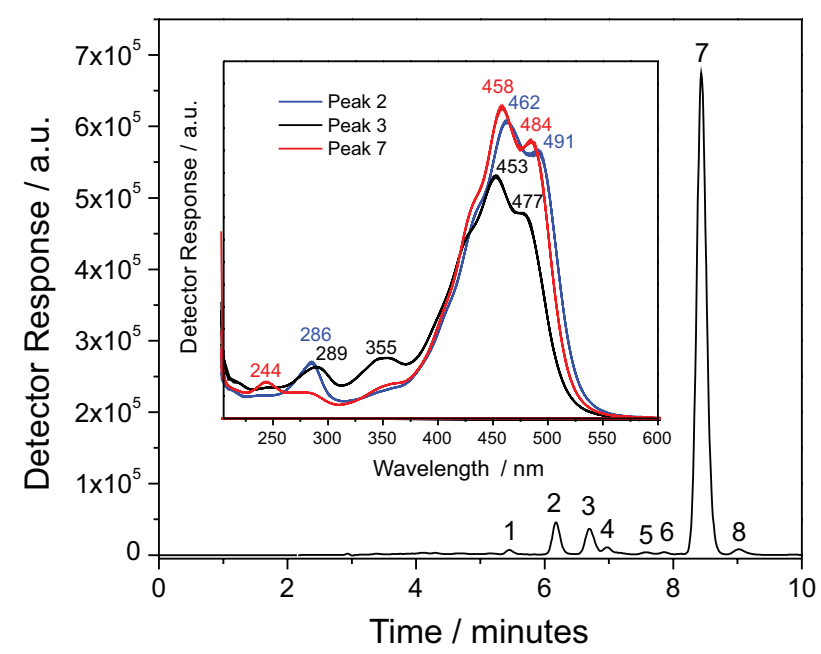

Figure 2. HPLC chromatogram of sample extracted from commercial hydrosoluble annatto extract. Inset: UV-Vis electronic spectra of peaks 2 (blue), 3 (black) and 7 (red).

Another isomer detected in considerable amount in the norbixin extracted sample is the 9',13'-di-cis-norbixin, which possesses two main bands at 452 and $476 \mathrm{~nm},{ }^{43}$ which are very close to the values obtained in the present study. Hence, peak 3 was associated to 9',13'-di-cis-norbixin. As observed in Figure 2, there were also other compounds detected in the norbixin sample in smaller quantities and are possibly related to one or two cis-double bonds, since other isomers are thermodynamically less stable and/or exhibit steric hindrance. ${ }^{15}$ Figure 3 shows the structures of the main norbixin isomers detected in this work using HPLC technique. It is noteworthy mentioning that upon dye 
intercalation into both $\mathrm{Zn}$ and $\mathrm{Mg} \mathrm{LDH}$-based matrices, the hybrid materials kept the norbixin characteristic orange color.<smiles>CC(/C=C/C=C/C(C)=C/C=C/C(=O)O)=C\C=C\C=C(C)\C=C\C=C(C)\C=C\C(=O)O</smiles><smiles>CC=CC(C)=CC=CC(C)=CC=CC=C(C)C=CC=C(C)C=CCO</smiles><smiles>CC(C)=CC=CC(C)=CC=CC(C)=CC=CC=C(C)C=CC(=O)O</smiles>

Figure 3. Main isomers of norbixin observed by HPLC in this study.

XRD patterns of norbixin and the intercalated $\mathrm{Zn}_{2} \mathrm{Al}$ and $\mathrm{Mg}_{2} \mathrm{Al}$ hybrid materials are shown in Figure 4. Norbixin exhibited a semicrystalline structure with high amorphous contribution owing to the presence of a broad signal

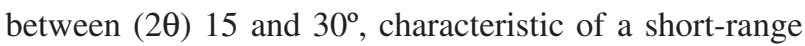
level of organization. However, a sharper signal at $(2 \theta) 26.2^{\circ}$ can be assigned to a higher extension of organization of the organic molecules, even though no attribution to this peak can be found in the literature. Also, the absence of sharp and intense peaks could indicate that the obtained norbixin was a mixture of isomeric species and other organic compounds, as aforementioned. On the other hand, XRD profile of LDH hybrids containing norbixin exhibited different features

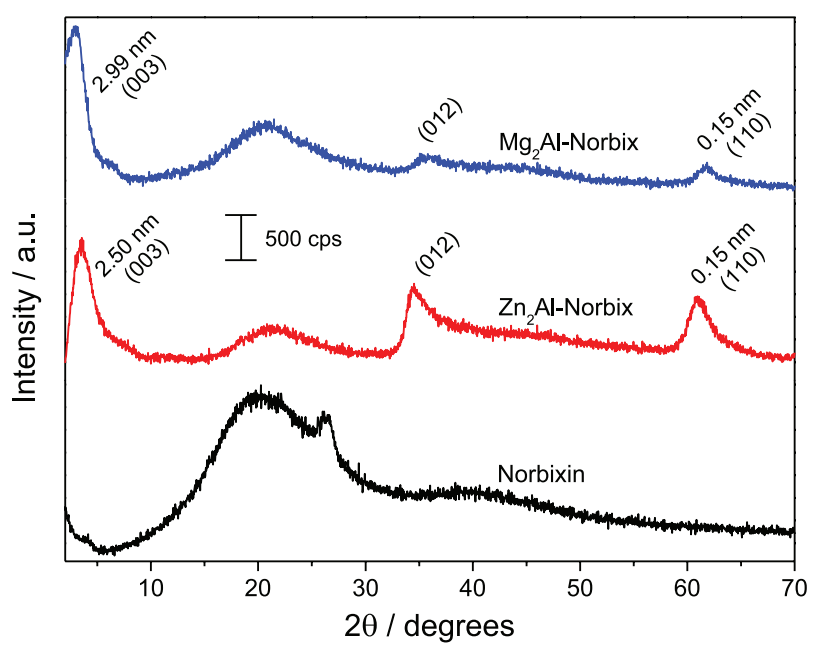

Figure 4. XRD patterns of norbixin, $\mathrm{Zn}_{2} \mathrm{Al}$-Norbix and $\mathrm{Mg}_{2} \mathrm{Al}$-Norbix samples. when compared to isolated norbixin. The reflection at (20) $61.0^{\circ}$ associated to the (110) planes indicates the formation of the hydroxide sheet in the layered structure. ${ }^{20}$

For both LDH materials, a defined reflection was observed at (2ө) 3.53 and $2.95^{\circ}$ for $\mathrm{Zn}_{2} \mathrm{Al}$-Norbix and $\mathrm{Mg}_{2} \mathrm{Al}$-Norbix, respectively, resulting in d-spacing values of 2.50 and $2.99 \mathrm{~nm}$. Considering that a single brucite layer possesses thickness of $0.48 \mathrm{~nm},{ }^{44}$ the interlayer spaces of $\mathrm{Zn}_{2} \mathrm{Al}-$ Norbix and $\mathrm{Mg}_{2} \mathrm{Al}$-Norbix are 2.02 and $2.51 \mathrm{~nm}$, respectively. Since $9^{\prime}$-cis-norbixin is the main species in the solid isolated from annatto extract, with dimensions $2.44 \times 0.63 \times 0.19 \mathrm{~nm}$ according to the computational modelling represented in the Figure 5a, different arrangements can be suggested depending on the cation composition of the $\mathrm{LDH}$ structure. For $\mathrm{Zn}_{2} \mathrm{Al}$-Norbix material, the d-spacing is smaller than the length of the molecule, what indicates that to accommodate the norbixin, a tilted arrangement between the norbixin backbone and the normal of the LDH sheet is required, as shown in Figure 5b, with an angle of about $56^{\circ}$ to satisfactorily fit the interlayer gap. $\mathrm{Mg}_{2} \mathrm{Al}$-norbix sample displayed a larger value of interlayer space compared to the zinc LDH but close to the length of norbixin, indicating that the organic species can be also arranged in a monolayer fashion but most probably perpendicularly to the adjacent layers.

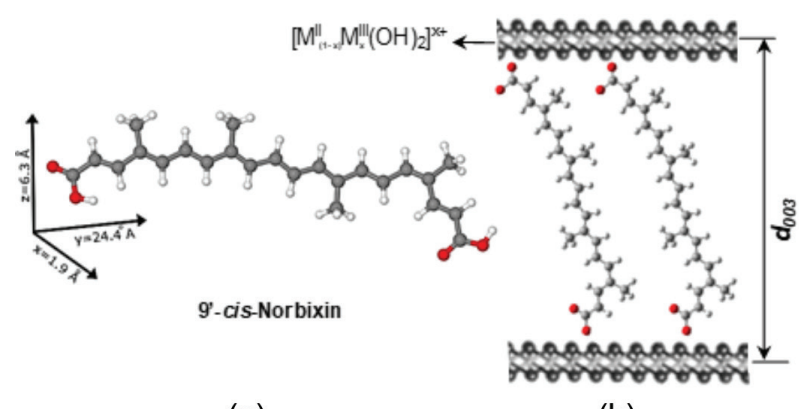

(a)

(b)

Figure 5. (a) 3D representation of 9'-cis-norbixin structure calculated by DFT, with the vectors indicating the average dimensions of the molecule. Atomic colors: grey $(\mathrm{C})$, white $(\mathrm{H})$ and red $(\mathrm{O})$; (b) scheme of one possible interlayer arrangement of norbixin between $\mathrm{LDH}$ layers.

From a commercial annatto dye, Kohno et al. ${ }^{45}$ reported the synthesis of a magnesium and aluminum LDH phase intercalated with norbixin by coprecipitation method. However, XRD pattern of the isolated material did not suggest the dye intercalation but adsorption on LDH external surfaces; no other characterization technique was reported. Later, Kohno et al. ${ }^{46}$ also investigated the immobilization of norbixin into a hydrotalcite intercalated together with dodecyl sulphate or dodecylbenzene sulfonate, i.e., a hydrophobic LDH, and the effect on the dye photostability under visible irradiation in air. 
The chemical integrity of norbixin after intercalation into LDH carriers can be assessed by vibrational spectroscopy. Studies comprising the normal-coordinate analysis of all-trans and 15-cis isomers of $\beta$-carotene, ${ }^{47}$ the semi-empirical calculation of all-trans bixin, ${ }^{48}$ and DFT calculations of all-trans norbixin ${ }^{17}$ were used for vibrational spectra attribution. Furthermore, the vibrational spectra of 9'-cis-norbixin isomer was calculated by DFT in this work. All calculated chemical shifts provided by DFT method are listed in Table 1 and a good linear correlation between experimental and DFT calculated frequencies (in wavenumber) values is seen in Figure S1 (see Supplementary Information (SI) section). The band assigned to the carboxylic group stretching $(v \mathrm{C}=\mathrm{O})$ was not considered in the correlation. Carboxylic acids can interact by hydrogen bonds in solid state which are found to shift the band to low energy region. The DFT calculation of norbixin was performed under vacuum environment, precluding intermolecular interactions. Indeed a mismatch between experimental $\left(1682 \mathrm{~cm}^{-1}\right)$ and calculated $\left(1762 \mathrm{~cm}^{-1}\right)$

Table 1. Raman and IR frequencies (in wavenumbers) of norbixin in the solid state, calculated vibrational frequencies (in wavenumbers) for 9'-cis-norbixin by DFT method, Raman and IR frequencies (in wavenumbers) of LDH-Norbix hybrids, and a tentative assignment

\begin{tabular}{|c|c|c|c|c|c|c|}
\hline \multicolumn{4}{|c|}{ Norbixin } & \multirow{2}{*}{\multicolumn{2}{|c|}{$\begin{array}{c}\text { LDH-Norbix } \\
\text { Experimental } / \mathrm{cm}^{-1} \\
\end{array}$}} & \multirow{3}{*}{ Assignment ${ }^{\mathrm{b}} / \mathrm{cm}^{-1}$} \\
\hline \multicolumn{2}{|c|}{ Calculated $/ \mathrm{cm}^{-1}$} & \multicolumn{2}{|c|}{ Experimental $/ \mathrm{cm}^{-1}$} & & & \\
\hline Without shift & With shift ${ }^{\mathrm{a}}$ & Raman & IR & Raman & IR & \\
\hline 1833 & 1762 & & $1682(\mathrm{~s})$ & & & $v(\mathrm{C}=\mathrm{O})$ carboxylic \\
\hline 1672 & 1607 & & $1608(\mathrm{~m})$ & & $1619(\mathrm{~s})$ & all $v(\mathrm{C}=\mathrm{C})$ \\
\hline \multirow[t]{2}{*}{1641} & 1578 & $1596(w)$ & $1596(\mathrm{sh})$ & $1597(w)$ & & all $v(\mathrm{C}=\mathrm{C})$ \\
\hline & & & & & 1558 (br) & $v_{\mathrm{as}}\left(\mathrm{COO}^{-}\right)$ \\
\hline 1627 & 1564 & & $1563(w)$ & & & all $v(\mathrm{C}=\mathrm{C})$ \\
\hline 1587 & 1526 & sh & & & & all $v(\mathrm{C}=\mathrm{C})$ \\
\hline 1576 & 1520 & $1520(\mathrm{~s})$ & sh & $1526(\mathrm{~s})$ & & all $v(\mathrm{C}=\mathrm{C})+\delta\left(\mathrm{CH}_{3}\right)_{\mathrm{a}, \mathrm{b}, \mathrm{c}}$ \\
\hline \multirow[t]{3}{*}{1501} & 1443 & $1445(w)$ & $1443(\mathrm{sh})$ & $1447(w)$ & $1447(\mathrm{sh})$ & $\delta\left(\mathrm{CH}_{3}\right)_{\mathrm{b}, \mathrm{c}}$ \\
\hline & & & $1422(w)$ & & $1422(\mathrm{sh})$ & all $\delta\left(\mathrm{CH}_{3}\right)$ \\
\hline & & & & & $1400(\mathrm{~s})$ & $v_{\mathrm{s}} \mathrm{COO}^{-}$ \\
\hline 1444 & 1388 & $1382(w)$ & $1382(w)$ & & $1385(\mathrm{~s})$ & all $\delta(\mathrm{C}=\mathrm{C}-\mathrm{H})+\delta\left(\mathrm{CH}_{3}\right)_{\mathrm{a}, \mathrm{b}}$ \\
\hline 1415 & 1360 & & & & & $\delta\left(\mathrm{C}=\mathrm{C}^{*}-\mathrm{H},{ }^{*}=8,10,11,12,14,15,15^{\prime}, 1^{\prime}, 10^{\prime}, 8^{\prime}\right)+$ all $\delta\left(\mathrm{CH}_{3}\right)$ \\
\hline 1327 & 1276 & $1285(w)$ & $1292-1271(w)$ & & & $\beta\left(\mathrm{C}=\mathrm{C}^{*}-\mathrm{H}, *=7,8,10,12,15,15^{\prime}, 14^{\prime}, 10^{\prime}, 8^{\prime}\right)$ \\
\hline 1322 & 1271 & & & & & $\beta\left(\mathrm{C}=\mathrm{C}^{*}-\mathrm{H}, *=11,11^{\prime}, 7^{\prime}\right)+$ all $v \mathrm{C}-\mathrm{COOH}$ \\
\hline 1311 & 1260 & & & & & $\beta\left(\mathrm{C}=\mathrm{C}^{*}-\mathrm{H}, *=7,8,10,11,15,15^{\prime}, 11^{\prime}, 7^{\prime}\right)+$ all $v(\mathrm{C}-\mathrm{COOH}$ \\
\hline 1306 & 1256 & & & & & all $\beta(C=C-H)$ \\
\hline 1288 & 1237 & & $1227(w)$ & & & $\beta\left(\mathrm{C}=\mathrm{C}^{*}-\mathrm{H}, *=8^{\prime}, 7^{\prime}\right)+\beta\left(\mathrm{C}^{\prime} \mathrm{O}-\mathrm{H}\right)$ \\
\hline 1260 & 1211 & $1218(w)$ & & & & all $\beta(\mathrm{C}=\mathrm{C}-\mathrm{H})$ \\
\hline 1230 & 1183 & 1200 (br) & $1188(w)$ & $1191(\mathrm{~m})$ & & $v\left(\mathrm{C}-\mathrm{CH}_{3}\right)_{\mathrm{a}, \mathrm{b}, \mathrm{c}}+$ all $\beta(\mathrm{C}=\mathrm{C}-\mathrm{H})$ \\
\hline 1202 & 1156 & $1152(\mathrm{~s})$ & & $1156(\mathrm{~s})$ & & $\beta\left(\mathrm{C}=\mathrm{C}^{*}-\mathrm{H}, *=15^{\prime}, 11^{\prime}\right)$ \\
\hline 1192 & 1146 & & & & & $\beta(\mathrm{C} 6 \mathrm{O}-\mathrm{H})$ \\
\hline 1177 & 1132 & $1133(\mathrm{~m})$ & $1133(w)$ & $1132(\mathrm{sh})$ & & all $\beta(\mathrm{O}-\mathrm{H})+$ all $\beta(\mathrm{C}=\mathrm{C}-\mathrm{H})+$ all $v\left(\mathrm{C}-\mathrm{CH}_{3}\right)+\delta\left(\mathrm{CH}_{3}\right)_{\mathrm{b}, \mathrm{c}, \mathrm{d}}$ \\
\hline 1141 & 1097 & & & & & $\beta\left(\mathrm{C}=\mathrm{C}^{\prime}-\mathrm{H}\right)+\beta\left(\mathrm{C}^{\prime}-\mathrm{O}-\mathrm{H}\right)+v\left(\mathrm{C}-\mathrm{CH}_{3}\right)_{\mathrm{a}}$ \\
\hline 1054 & 1013 & $1010(\mathrm{~m})$ & $1009(w)$ & $1010(\mathrm{~m})$ & $1010(w)$ & $\tau\left(\mathrm{CH}_{3}\right)_{\mathrm{a}, \mathrm{d}}$ \\
\hline 1034 & 994 & & $976(\mathrm{~m})$ & & $972(w)$ & $\mathrm{w}\left(\mathrm{CH}_{3}\right)_{\mathrm{b}, \mathrm{d}}$ \\
\hline \multirow[t]{4}{*}{1014} & 976 & & $956(\mathrm{~m})$ & $959(w)$ & & all $\gamma\left(\mathrm{CH}_{3}\right)$ \\
\hline & & & & & $620(\mathrm{br})$ & $\delta_{\mathrm{s}}(\mathrm{Al}-\mathrm{O}-\mathrm{Al})$ \\
\hline & & & & & $560(\mathrm{br})$ & $v_{\text {as }}\left(\mathrm{M}^{\mathrm{II}}-\mathrm{O}-\mathrm{Al}\right)_{\mathrm{L}}$ \\
\hline & & & & & $420(w)$ & $\delta_{\text {as }}\left(\mathrm{M}^{\mathrm{II}}-\mathrm{O}-\mathrm{Al}\right)_{\mathrm{L}}$ \\
\hline
\end{tabular}

The selected values of wavenumbers $\left(\mathrm{cm}^{-1}\right)$ are multiplied by 0.9614 , according to the computational calculations description; ${ }^{\mathrm{b}}$ see carbon numeration and indexes a, b, c, d in Figure 3; $v$ : stretching; $\delta$ : bending; $\beta$ : bending in plane; $\gamma$ : bending out of plane; w: wagging; $\tau$ : rocking; s: symmetric; as: antisymmetric; br: broad; sh: shoulder; w: weak; m: medium; s: strong; L: lattice; $\mathrm{M}^{\mathrm{II}}$ : divalent cation. 
frequency values for $v(\mathrm{C}=\mathrm{O})$ vibration was observed with carboxylic acid molecules as in other studies. ${ }^{28}$

Figure 6 shows the vibrational spectra of norbixin isolated in this work and those calculated for 9'-cis-norbixin isomer. The bands between $1608-1445 \mathrm{~cm}^{-1}$ are assigned to $v(\mathrm{C}=\mathrm{C})$ while those ranging in the $1220-1130 \mathrm{~cm}^{-1}$ are related to $v(\mathrm{C}-\mathrm{C})$ and to the deformation of $\mathrm{C}=\mathrm{C}-\mathrm{H}$. The Raman spectrum of norbixin is very similar to those ones of carotenoids and dominated by the bands associated to the conjugated carbon skeleton $\left(1520,1152\right.$ and $\left.1010 \mathrm{~cm}^{-1}\right){ }^{47,48}$ The bands related to the carboxylic group are visualized in the IR spectrum. The band assigned to the stretching of $\mathrm{C}-\mathrm{COOH}$ (C6-C7 bonding, Figure 3) is expected at about $1271-1260 \mathrm{~cm}^{-1}$ while the bands attributed to the in-plane deformation of $\mathrm{O}-\mathrm{H}(\mathrm{O}=\mathrm{CO}-\mathrm{H})$ are depicted mainly at about $1146-1097 \mathrm{~cm}^{-1}$ (Table 1 ). Kim et al. ${ }^{49}$ observed the FTIR bands of norbixin at 1670, 1610, 1558, 1424, 1312, 1282, 1260, 1193, 1141, 1006 and $954 \mathrm{~cm}^{-1}$. These frequency values do not totally match the data on Table 1, as well as the IR spectral profile shown in Figure 6, and is not entirely coincident with that one recorded by Reith and Gielen ${ }^{50}$ for cis-norbixin. The IR spectrum of norbixin should be dependent of the geometric isomers in the sample (noticed that cis- and trans-norbixin have distinct vibrational spectra $)^{50}$ and of the precipitation

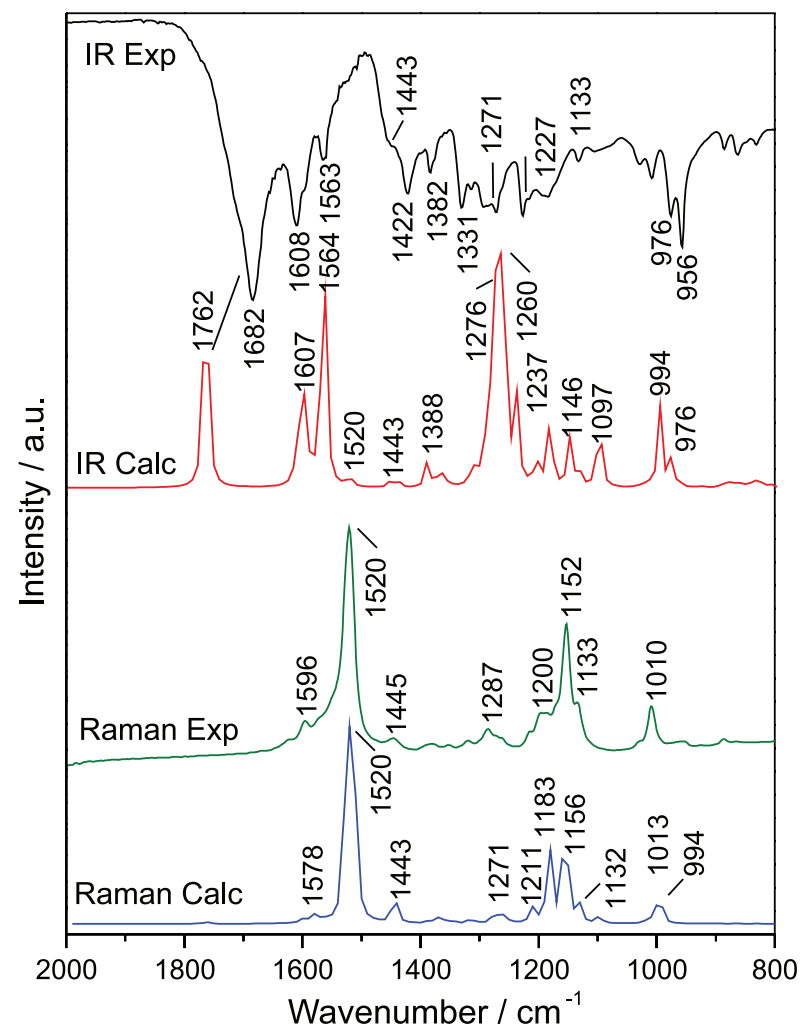

Figure 6. IR spectra (superior) of experimental norbixin and calculated 9'-cis-norbixin; Raman spectra (inferior) of experimental norbixin and calculated 9'-cis-norbixin. conditions from the extract, since the non-crystalline nature of norbixin enables different possibilities of intermolecular interactions in the solid state.

After norbixin intercalation into LDH matrices, the Raman spectra are similar to the protonated dye since the main bands at 1526, 1156 and $1010 \mathrm{~cm}^{-1}$ (Figure 7) are related to the carbon chain as aforementioned. However, the narrow bands assigned to $v(\mathrm{C}=\mathrm{C})$ and $v(\mathrm{C}-\mathrm{C})$ are shifted towards higher energy region upon intercalation (from 1520 to $1526 \mathrm{~cm}^{-1}$ and from 1152 to $1156 \mathrm{~cm}^{-1}$, respectively), Table 1 , possibly owing to the influence of dye deprotonation in the conjugated carbon chain. Maia et al. ${ }^{51}$ studied the interactions among cis-bixin in several solvents analyzing the modifications in the dye Raman spectral profile. The authors observed an increase in the value of $v(\mathrm{C}=\mathrm{C})$ band comparing the cis-bixin spectrum in solid state and in solution, that was related to the solvent polarizability. However, the shift of $v(\mathrm{C}-\mathrm{C})$ band at $1152 \mathrm{~cm}^{-1}$ of cis-norbixin observed in this work after intercalation was not perceived for cis-bixin in the different solvents. Hence, the modifications in Raman spectrum of no-intercalated norbixin compared to the intercalated form (Figures 6 and 7, respectively) can also be related to the molecule environment.

Contrary to the Raman spectroscopic data, a significant reduction in the number of bands is observed in the IR spectra after norbixin interleaved into the host (Figure 7). The band at $1682 \mathrm{~cm}^{-1}$ assigned to $v(\mathrm{C}=\mathrm{O})$ shows significant decrease of intensity while the new bands at 1558 and $1400 \mathrm{~cm}^{-1}$ can be assigned to $v_{\text {as }} \mathrm{COO}^{-}$and $v_{\mathrm{s}} \mathrm{COO}^{-}$vibrational modes, respectively, ${ }^{26-28}$ signaling the presence of deprotonated/anionic norbixin between the layers. It is also noted that after intercalation, the band attributed to $v(\mathrm{C}=\mathrm{C})$ in the IR spectrum of norbixin is shifted towards higher frequency values (from 1608 to $1619 \mathrm{~cm}^{-1}$ ), suggesting once more that the carbon-carbon bond length might be slightly decreased due to norbixin deprotonation. Around $1382 \mathrm{~cm}^{-1}$, the protonated organic dye exhibits a band that is associated to the bending of $\mathrm{C}-\mathrm{H}$ and $-\mathrm{CH}_{3}$ groups present along the main backbone which are still present after intercalation, indicating that although confined, norbixin chains are not densely packed inside the interlayer domain. At the low wavenumber region (below $1000 \mathrm{~cm}^{-1}$ ) both LDH samples showed broad bands that are attributed to $\mathrm{M}-\mathrm{O}-\mathrm{H}$ bending and $\mathrm{M}-\mathrm{O}$ stretching modes, ${ }^{52,53}$ corroborating the XRD data for the formation of the inorganic layered phase.

According to thermal data presented in Figure 8, isolated norbixin undergoes mainly four decomposition steps under oxidizing atmosphere. Oxidative events are the main forms of mass loss according to the differential 


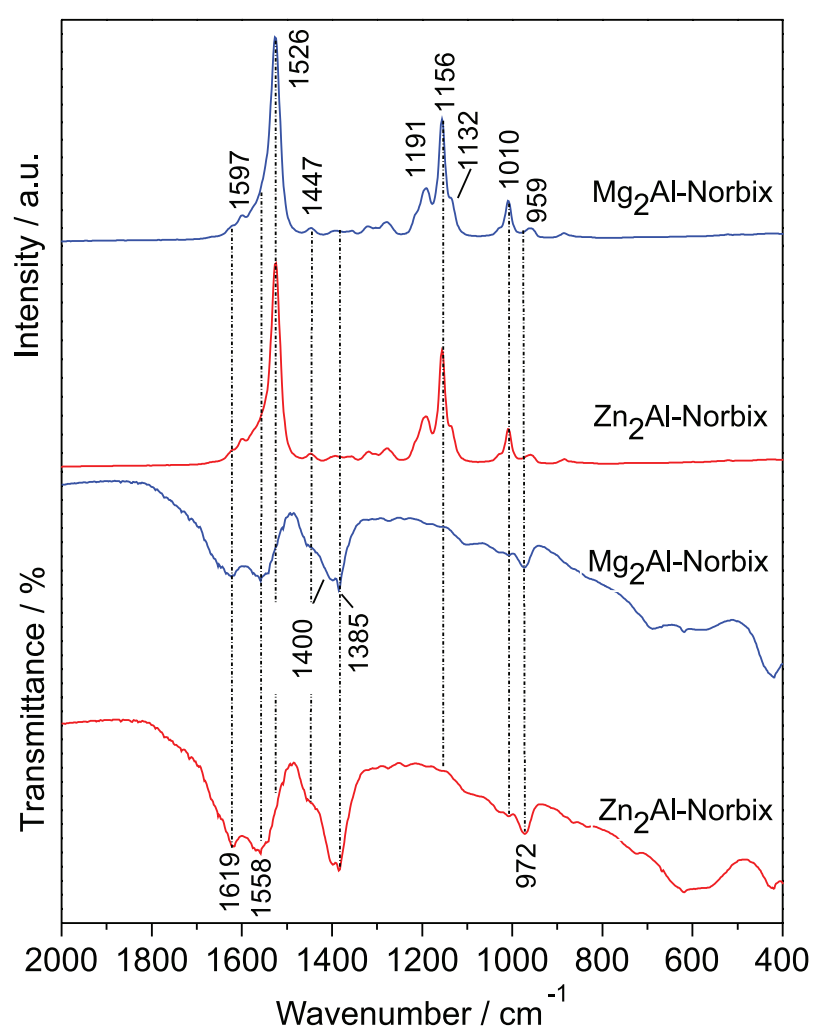

Figure 7. Raman spectra (superior) and FTIR spectra (inferior) of $\mathrm{M}_{2} \mathrm{Al}-$ Norbix samples $\left(\mathrm{M}=\mathrm{Mg}^{2+}\right.$ or $\left.\mathrm{Zn}^{2+}\right)$.

scanning calorimetry (DSC) curves owing to the exothermic nature associated to all steps and no melting process is observed along the analysis. From around $170^{\circ} \mathrm{C}$ and up to $300^{\circ} \mathrm{C}$, norbixin decomposes releasing mainly fragments with $m / z$ equals $18\left(\mathrm{H}_{2} \mathrm{O}\right)$ and $44\left(\mathrm{CO}_{2}\right)$ and loss around $35.3 \%$ of mass.

The profile of the TG curve shown in Figure 8 is similar to that one presented by Silva et al. ${ }^{54}$ for $c i s$-norbixin (extracted from annatto) up to $400^{\circ} \mathrm{C}$ (about $50 \%$ of mass loss) under nitrogen atmosphere and $10{ }^{\circ} \mathrm{C} \mathrm{min}^{-1}$ heating rate. At higher temperature values, the thermal behavior is distinct: mass loss is extended to ca. $700{ }^{\circ} \mathrm{C}$ and a residue is observed.

For the LDH-Norbix hybrids, the thermal decomposition profile (Figure 9) is significantly changed since its chemical environment is severely modified after confinement between the inorganic layers. The main volatiles generated are the previous mentioned molecules for norbixin samples.

From 200 to $400{ }^{\circ} \mathrm{C}$, the $\mathrm{Zn}_{2} \mathrm{Al}$-Norbix (Figure 9a) anhydrous intercalated sample decreased its mass by $26.1 \%$ after oxidative reaction of norbixin chains with molecular oxygen, yielding water and carbon dioxide molecules. In comparison to norbixin, which starts the decomposing event at $170{ }^{\circ} \mathrm{C}$ (Figure 8), a shift towards higher temperature values is observed due to the decomposition of intercalated organic chains (release of $\mathrm{CO}_{2}$ ). This effect can be attributed to the reduced contact of the organic content with molecular oxygen from the analysis atmosphere. The metal hydroxides layers, that act as a barrier to the gas diffusion, hinder the beginning of the oxidative step, and also affects the reactivity of the guest structure after intercalation. ${ }^{55}$ Concomitantly, in the temperature range from 200 to $400{ }^{\circ} \mathrm{C}, \mathrm{LDH}$ matrix undergoes dehydroxylation of the layers and the release of water molecules occurs. ${ }^{26,28}$

Similarly, $\mathrm{Mg}_{2} \mathrm{Al}$-Norbix thermal decomposition process (Figure 9b) exhibits several steps of mass loss as observed for $\mathrm{Zn}_{2} \mathrm{Al}$-Norbix. Two mass loss events associated to the release of adsorbed water molecules $(\mathrm{m} / \mathrm{z}=18$; mass loss of 7.4\%) were recorded for $\mathrm{Mg}_{2} \mathrm{Al}$-Norbix up to about $150{ }^{\circ} \mathrm{C}$. In the $200-550^{\circ} \mathrm{C}$ temperature range, the thermal decomposition profile is very similar to that one observed

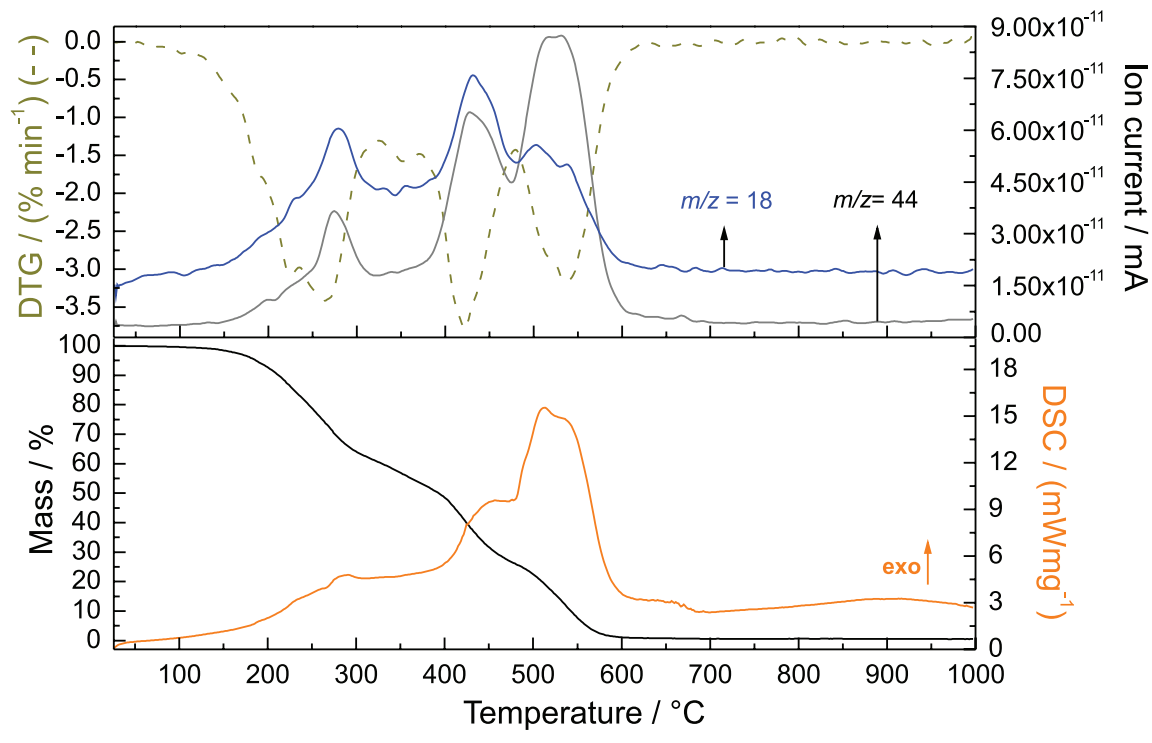

Figure 8. TG (black), DTG (dashed green), DSC (orange) and MS (blue and grey) curves of norbixin. 

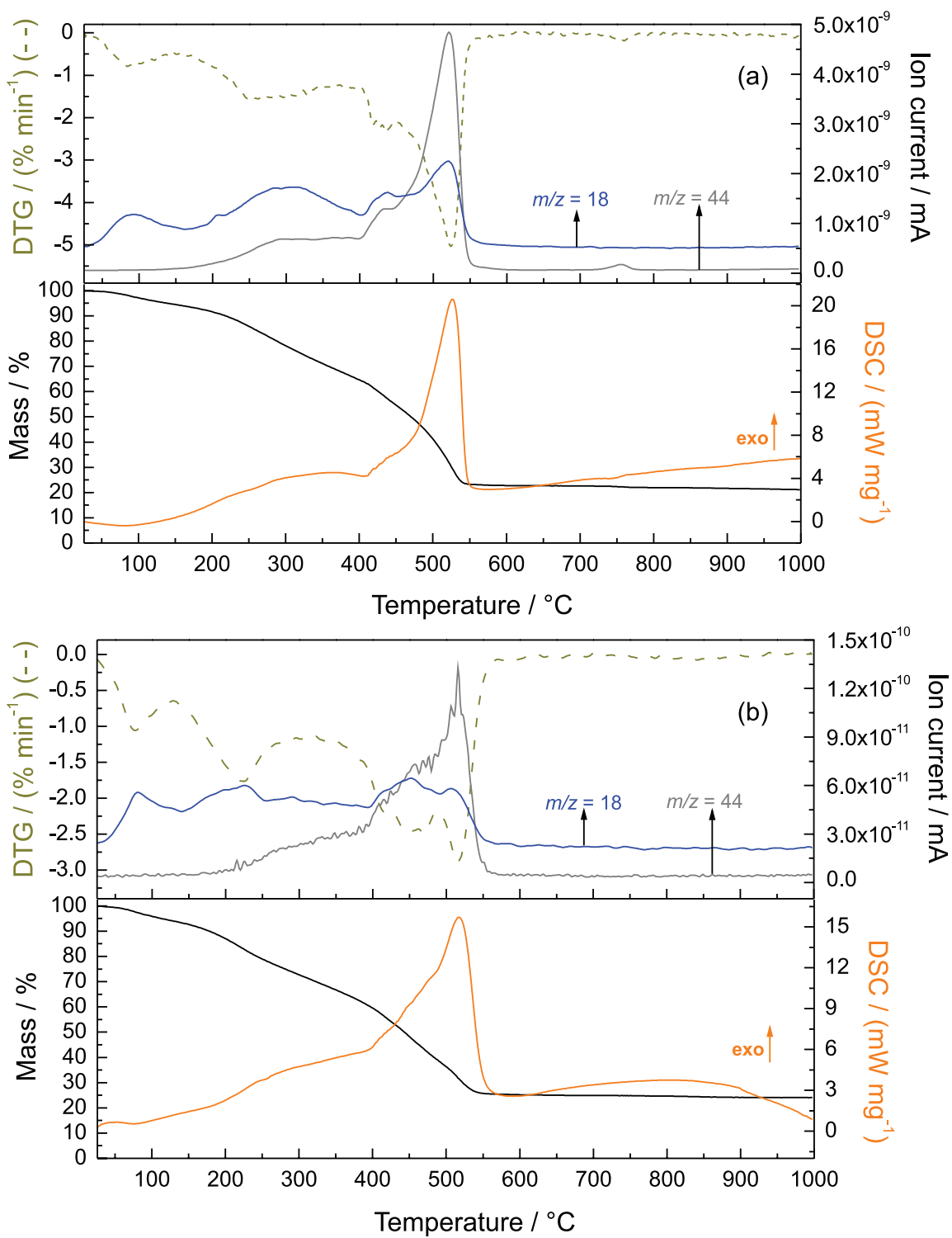

Figure 9. TG (black), DTG (dashed green), DSC (orange) and MS (blue and grey) curves of (a) $\mathrm{Zn}_{2} \mathrm{Al}-\mathrm{Norbix}$ and (b) $\mathrm{Mg}_{2} \mathrm{Al}-\mathrm{Norbix}$ samples.

for $\mathrm{Zn}_{2} \mathrm{Al}$-Norbix. Further information and discussion about the thermal events observed to the evaluated materials can be found in the SI section.

Thermal analysis and elemental chemical analysis were performed to estimate the water content, and CHN and metals, respectively, in the samples isolated in this study. The solid obtained from hydrosoluble annatto extract exhibited 70.0 wt.\% of carbon, 8.15 wt.\% of hydrogen and no solvent molecules in the structure. Considering the molecular formula of norbixin $\left(\mathrm{C}_{24} \mathrm{H}_{28} \mathrm{O}_{4}\right.$, $380 \mathrm{~g} \mathrm{~mol}^{-1}$ ), calculated values expected are $75.8 \mathrm{wt} . \%$ of carbon and 7.30 wt. $\%$ of hydrogen. Hence, minor amount of species with lower carbon content than norbixin was present in the isolated solid sample. Among the chemical constituents of Bixa orellana, a terpene alcohol of molecular formula $\mathrm{C}_{20} \mathrm{H}_{34} \mathrm{O}$ (geranylgeraniol) constitutes the major oily compound of dry seeds of annatto (about 1\%). ${ }^{56}$ Both $\mathrm{Zn}_{2} \mathrm{Al}$-Norbix and $\mathrm{Mg}_{2} \mathrm{Al}$-Norbix samples have $\mathrm{M}^{2+} / \mathrm{Al}^{3+}$ molar ratio equal to 1.9 , and respectively 42.3 and $45.8 \mathrm{wt} . \%$ of carbon, 6.67 and $6.45 \mathrm{wt} . \%$ of hydrogen, and 5.6 and 7.4 wt.\% of water content. Considering the experimental molar ratio of metals and anhydrous hybrid materials, the experimental amount of carbon in $\mathrm{Mg}_{2} \mathrm{Al}$-Norbix (45.8\%), for instance, is higher than the value expected for the intercalated anionic norbixin (-2) (about $40 \%)$ and lower than calculate for the intercalated anionic norbixin (-1) (ca. 52\%). Since coprecipitation syntheses of the hybrid materials were conducted at different $\mathrm{pH}$ values (7 for Zn-based and around 9-10 for Mg-based LDH), and taking into consideration that the $\mathrm{p} K_{\mathrm{a}}$ value of the dye has not been determined experimentally but calculated theoretically as $4.768,{ }^{57}$ norbixin should be mainly in the 
dianion form in both samples. Furthermore, FTIR spectra of LDH-Norbix samples did not show significant absorption in the $1680 \mathrm{~cm}^{-1}$ region associated to the $\mathrm{C}=\mathrm{O}$ stretching of carboxylic group, precluding the presence of the norbixin monoanion. Nevertheless, the amount of organic species in the host matrices is appreciable.

The isolated norbixin and the LDH-Norbix materials were also characterized by solid state ${ }^{13} \mathrm{C}$ NMR (Figure S2, SI section). The NMR signals recorded in the solid-state are broader than those obtained in solution but possibly the presence of norbixin isomers also contributes for such effect. Based on the assignment of ${ }^{13} \mathrm{C}$ NMR of carotenoids, ${ }^{58}$ the signals observed in norbixin spectrum at $10-20 \mathrm{ppm}$ are attributed to methyl carbons bounded to C9, C13 and C13' while methyl carbon linked to C9' is observed at $23 \mathrm{ppm}$, as indicated in Figure S2. The signals of methylene carbons are noticed in the 120-130 ppm region. Carbons of carboxylic groups (C6/C6') are observed at about $173 \mathrm{ppm}$. The norbixin spectrum exhibited unexpected signals in the $30-40 \mathrm{ppm}$ and $60-70 \mathrm{ppm}$ region, indicating the presence of other compounds from the annatto extract in addition to norbixin.

Tirimanna ${ }^{59}$ identified other xanthophylls dyes in the seeds of annatto such as lutein (Figure 1c) and zeaxanthin, in which ${ }^{13} \mathrm{C}$ NMR spectra show peaks that could be assigned to the carbon atoms of the cyclohexane ring, as follow: ${ }^{58,60} \mathrm{CH}_{3}$ (20-30 ppm), carbon bounded to methyl groups (around $35 \mathrm{ppm}),>\mathrm{CH}_{2}(42-48 \mathrm{ppm})$ and $\mathrm{C}-\mathrm{OH}$ $(65.0 \mathrm{ppm})$. In other study, Costa and Chaves ${ }^{61}$ reported the presence of bixin and geranylgeraniol in the extract obtained treating annatto seeds with a solution of $5 \% \mathrm{NaOH}$. The ${ }^{13} \mathrm{C}$ NMR spectrum of all-trans-geranylgeraniol in $\mathrm{CDCl}_{3}$ shows peaks in the 30-40 and 60-70 ppm regions: ${ }^{62}>\mathrm{CH}_{2}$ (26.6 and 39.7 ppm) and C-OH (59.4 ppm). Xanthophylls and geranylgeraniol may be associated to norbixin in the alkaline extract of annatto used in this study through the hydrophobic carbon chain and the polar oxygenated (alcohol and carboxylate) groups, generating aggregates. The precipitation of the apocarotenoid by acidification could carry the xanthophylls and terpene alcohol to the solid state. Hence, the extra signals showed in Figure S2 can be satisfactorily ascribed to other oxygenated compounds present in the annatto extract.

The ${ }^{13} \mathrm{C}$ NMR spectra of LDH-Norbix are similar to that of norbixin but with modifications in the $\mathrm{C} 6$ and $\mathrm{C} 6$ ' region. The signal/noise ratio is low for $\mathrm{Mg}_{2} \mathrm{Al}$-Norbix sample, but two peaks are visualized for $\mathrm{Zn}_{2} \mathrm{Al}$-Norbix at about 175 and $183 \mathrm{ppm}$, suggesting that the carboxylate groups are not equivalent in the intercalated species. Additionally, the extra peaks assigned to other oxygenated compounds of annatto seeds are noticed, indicating that these species are interacting with norbixin between the interlayer space and/or the external surfaces. This fact can corroborate the superior carbon amount in the hybrid samples than the expected values. The immobilization of species such as lutein or geranylgeraniol in the synthesized samples is not harmful since they are no toxic and present therapeutic properties. ${ }^{63-65}$

The radical scavenger capacity of norbixin solutions and LDH-Norbix materials was evaluated by reaction with the stable DPPH free radical. This probe species supports an odd electron in the nitrogen atom that is reduced to hydrazine by an antioxidant that transfers hydrogen atom. ${ }^{66}$ The reduced DPPH species is diamagnetic (EPR silent). EPR spectra of a DPPH radical in ethanol solution were registered after addition of different amounts of norbixin (in solution or intercalated into LDH). First, $1500 \mu \mathrm{L}$ norbixin ethanol solution $\left(2.5 \mathrm{mmol} \mathrm{L}^{-1}\right)$ were added to $500 \mu \mathrm{L} \mathrm{DPPH}\left(2.03 \mathrm{mmol} \mathrm{L}^{-1}\right.$, in ethanol) and the reaction was monitored up to $5 \mathrm{~h}$. A decrease in the radical signal with time was observed, as shown in Figure 10, indicating a first-order kinetics (regression equation found: $y=0.285+0.541 \mathrm{e}^{-x / 190}$, with $\left.\mathrm{R}^{2}=0.993\right)$. These data attested a remarkable spin scavenger activity of norbixin, probably forming non-radical products since no other signal was detected in the experiment. Carotenoids can react primarily with radicals through reactions involving electron transfer, hydrogen abstraction or addition. ${ }^{67}$

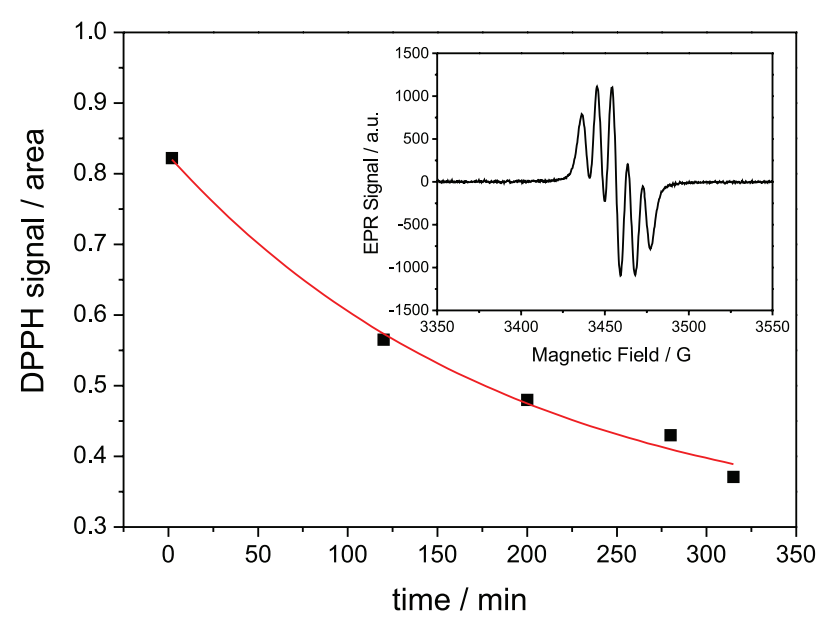

Figure 10. Radical scavenging capacity of norbixin $\left(1.9 \mathrm{mmol} \mathrm{L}^{-1}\right)$ versus time, towards DPPH ethanol solution $\left(0.40 \mathrm{mmol} \mathrm{L}^{-1}\right)$ at room temperature, up to $300 \mathrm{~min}$. Insert: initial DPPH spectrum $\left(2.5 \mathrm{mmol} \mathrm{L}^{-1}\right)$.

Further analogues experiments were carried out with norbixin intercalated in both $\mathrm{Zn}$ and Mg-based LDH. Similarly, according to the Figure 11, a significant decrease of DPPH radical signal was also verified for both materials, attesting that the radical scavenging ability of norbixin is maintained even after intercalation within LDH galleries. 
Interestingly, the matrix composition affects the norbixin reactivity. The $\mathrm{Mg}_{2} \mathrm{Al}$-Norbix material was more effective than the analogous $\mathrm{Zn}_{2} \mathrm{Al}$-Norbix regarding the DPPH depletion, especially at longer time periods. After $200 \mathrm{~min}$, for instance, the amount of consumed DPPH radical was about $80 \%$ for $\mathrm{Mg}_{2} \mathrm{Al}-\mathrm{Norbix}$ and $50 \%$ for the zinc-LDH. A plausible explanation could be a higher stabilization of DPPH radical in the material containing zinc.

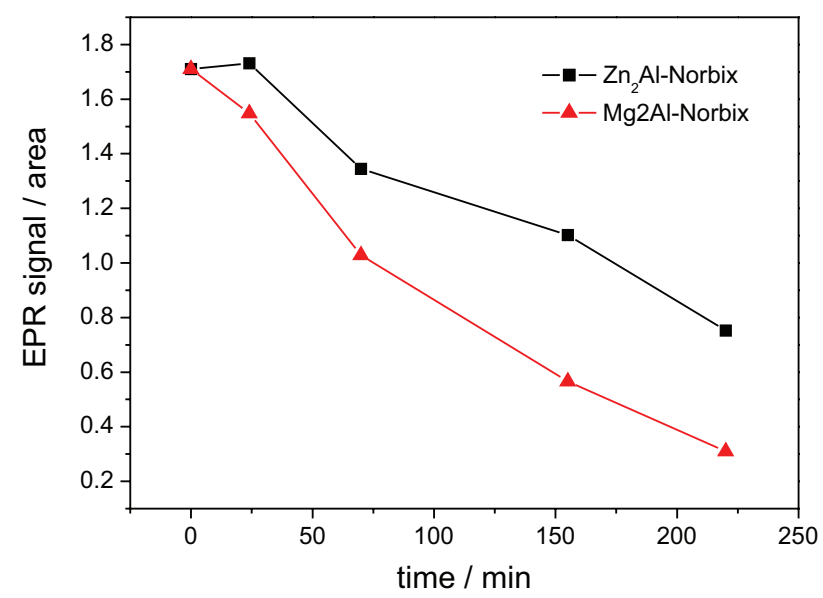

Figure 11. Radical scavenging capacity against DPPH ethanol solution $\left(1 \mathrm{mmol} \mathrm{L}{ }^{-1}\right.$ ) for $\mathrm{Zn}_{2} \mathrm{Al}$-Norbix (black) and $\mathrm{Mg}_{2} \mathrm{Al}$-Norbix (red) samples (40 mg).

\section{Conclusions}

Apocarotenoids of annatto dye were for the first time intercalated into $\mathrm{LDH}$, a two-dimensional structured material, by one-pot method. The dimension of LDH interlayer space is large enough to assure the norbixin to be well ensconced. Indeed, the dye is found to be arranged in a perpendicular/tilted orientation in relation to the inorganic layers. The vibrational spectroscopic characterization was performed using experimental and theoretical techniques, providing a systematic and thoughtful analysis. FTIR spectra indicated the presence of deprotonated norbixin in the confined space and the chemical integrity of the dye after its intercalation process. The profile of thermal decomposition of interleaved organic species is changed compared to the free species and the release of carbon dioxide from the organic chains occurs at higher temperature values owing to the protective barrier created by the LDH structure through its host-guest feature. ${ }^{13} \mathrm{C}$ NMR spectra of extracted norbixin and the LDH-Norbix hybrids indicate the presence of other oxygenated compounds (probably xanthophylls and terpene alcohol) associated to norbixin. The carbon contents in the hybrid materials are higher than the values expected for a dianion form of norbixin, which can be related to the co-intercalation of the neutral oxygenated compounds aforementioned. Norbixin maintains its antioxidant property after intercalation, which is dependent of the layers composition, opening new opportunities to investigate the biological activity of such hybrid materials or their potential usage as filler in nanocomposites domain.

\section{Supplementary Information}

Supplementary data are available free of charge at http://jbcs.sbq.org.br as PDF file.

\section{Acknowledgments}

G. F. P. and F. F. S. acknowledge the Conselho Nacional de Desenvolvimento Científico e Tecnológico (CNPq) for the scholarships. V. R. L. C., A. M. D. C. F. and H. M. P. are thankful to the Fundação de Amparo à Pesquisa do Estado de São Paulo (FAPESP) for the financial support (2011/50318, 2013/07937-8, 2014/50869-6) and to CNPq for the research grants (305446/2017-7, 304776/2014-9 and 311373/2018-6, respectively). H. M. P. and F. C. D. A. L. are thankful to CNPq for the financial support (428211/2018-6) and the computational time provided by USP-HPC and CENAPAD/SP. The authors thank Christian Hansen Ind. e Com. Ltda. (Brazil) for the annatto extract offering. Laboratório de Espectroscopia Molecular (LEM, Instituto de Química-USP) is acknowledged for the Raman spectra recording. Aparício and Marcia Temperini are acknowledged for the nice pictures of annatto tree and fruits.

\section{Author Contributions}

G. F. P. and F. F. S. extracted norbixin from annatto, prepared the LDH materials, and performed characterization. R. A. A. C. conducted HPLC analysis and interpretation. F. C. D. A. L. and H. M. P. performed DFT calculation, vibrational spectra simulation and attribution. F. L. analyzed the data from LDH structural characterization, recorded and interpreted NMR spectra. A. M. C. F. conducted the EPR experiments and the data interpretation. G. F. P. and V. R. L. C. analyzed and interpreted the characterization data, and wrote the paper. V. R. L. C. headed the investigation and elaborated the experimental scheme. All authors revised the manuscript.

\section{References}

1. http://www.fao.org/gsfaonline/additives/details. $\mathrm{html}$ ?id=391\&d-3586470-o=2\&d-3586470-s=5, accessed in March 2020. 
2. Islam, S.; Rather, L. J.; Mohammad, F.; J. Adv. Res. 2016, 7, 499.

3. Chisté, R. C.; Mercadante, A. Z.; Gomes, A.; Fernandes, E.; Lima, J. L. F. D. C.; Bragagnolo, N.; Food Chem. 2011, 127, 419.

4. Vilar, D. D. A.; Vilar, M. S. D. A.; Moura, T. F. A. D. L.; Raffin, F. N.; Oliveira, M. R. D.; Franco, C. F. D. O.; Athayde-Filho, P. F. D.; Diniz, M. D. F. F. M.; Barbosa-Filho, J. M.; Sci. World J. 2014, ID 857292.

5. Júnior, R. G. O.; Bonneta, A.; Braconnier, E.; Groult, H.; Prunier, G.; Beaugeard, L.; Grougnet, R.; Almeida, J. R. G. S.; Ferraz, C. A. A.; Picot, L.; Food Chem. Toxicol. 2019, 125, 549.

6. Afonso, C. R.; Hirano, R. S.; Gaspar, A. L.; Chagas, E. G. L.; Carvalho, R. A.; Silva, F. V.; Leonardi, G. R.; Lopes, P. S.; Silva, C. F.; Yoshida, C. M. P.; Int. J. Biol. Macromol. 2019, $132,1262$.

7. Roehrsa, M.; Conte, L.; da Silva, D. T.; Duarte, T.; Maurer, L. H.; de Carvalho, J. A. M.; Moresco, R. N.; Somacal, S.; Emanuelli, T.; Food Res. Int. 2017, 100, 771.

8. Júnior, A. C.; Asad, L. M.; Oliveira, E. B.; Kovary, K.; Asad, N. R.; Felzenszwalb, I.; Genet. Mol. Res. 2005, 4, 94.

9. Galindo-Cuspinera, V.; Rankin, S. A.; J. Agric. Food Chem. 2005, 53, 2524.

10. Lima, L. R. P.; Oliveira, T. T.; Nagem, T. J.; Pinto, A. S.; Stringheta, P. C.; Tinoco, A. L. A.; Silva, J. F.; Braz. J. Vet. Res. An. Sci. 2001, 38, 196.

11. Fontaine, V.; Monteiro, E.; Brazhnikova, E.; Lesage, L.; Balducci, C.; Guibout, L.; Feraille, L. L.; Elena, P.-P.; Sahel, J.-A.; Veillet, S.; Lafont, R.; PLoS One 2016, 11, e0167793.

12. International Union of Pure and Applied Chemistry (IUPAC); Compendium of Chemical Terminology, The "Gold Book", $2^{\text {nd }}$ ed.; McNaught, A. D.; Wilkinson, A., eds; Blackwell Scientific Publications: Oxford, 1997. Available at https://goldbook.iupac. org/terms/view/C00858, acessed in March 2020.

13. https://www.qmul.ac.uk/sbcs/iupac/carot/car1t7.html, accessed in March 2020.

14. Meléndez-Martínez, J.; Mapelli-Brahm, P.; Hornero-Méndez, D.; Vicario, I. M. In Carotenoid Esters in Foods: Physical, Chemical and Biological Properties; Mercadante, A. Z., ed.; The Royal Society of Chemistry: London, UK, 2019, ch. 1, $1-50$.

15. Scotter, M.; Food Addit. Contam., Part A 2009, 26, 1123.

16. Marcolino, V. A.; Zanin, G. M.; Durrant, L. R.; Benassi, M. T.; Matioli, G.; J. Agric. Food Chem. 2011, 59, 3348.

17. de Oliveira, V. E.; Almeida, E. W. C.; Castro, H. V.; Edwards, H. G. M.; dos Santos; H. F.; de Oliveira, L. F. C.; J. Phys. Chem. A 2011, 115, 8511.

18. de Marco, R.; Vieira, A. M. S.; Ugri, M. C. A.; Monteiro, A. R. G.; Bergamasco, R. C.; Chem. Eng. Trans. 2013, 32, 1777.

19. Tupuna, D. S.; Paese, K.; Guterres, S. S.; Jablonski, A.; Flôres, S. H.; Rios, A. O.; Ind. Crops Prod. 2018, 111, 846.
20. Evans, D. G.; Slade, R. C. T. In Layered Double Hydroxides, vol. 119; Duan, X.; Evans, D. G., eds.; Springer: Berlin, 2006, ch. 1, p.1-87.

21. Mishra, G.; Dash, B.; Pandey, S.; Appl. Clay Sci. 2018, 153, 172.

22. Oh, J. M.; Park, D. H.; Choi, S. J.; Choy, J. H.; Recent Pat. Nanotechnol. 2012, 6, 200.

23. Cunha, V. R. R.; Ferreira, A. M. C.; Constantino, V. R. L.; Tronto, J.; Valim, J. B.; Quim. Nova 2010, 33, 159.

24. https://www.drugs.com/international/hydrotalcite.html, accessed in March 2020.

25. Shen, S.; Wu, Y.; Liu, Y.; Wu, D.; Int. J. Nanomed. 2017, 12, 4085.

26. Cunha, V. R. R.; Petersen, P. A. D.; Gonçalves, M. B.; Petrilli, H. M.; Taviot-Gueho, C.; Leroux, F.; Temperini, M. L. A.; Constantino, V. R. L.; Chem. Mater. 2012, 24, 1415.

27. Cunha, V. R. R.; Guilherme, V. A.; de Paula, E.; de Araujo, D. R.; Silva, R. O.; Medeiros, J. V. R.; Leite, J. R. S. A.; Petersen, P. A. D.; Foldvari, M.; Petrilli, H. M.; Constantino, V. R. L.; Mater. Sci. Eng., C 2016, 58, 629.

28. Rocha, M. A.; Petersen, P. A. D.; Teixeira-Neto, E.; Petrilli, H. M.; Leroux, F.; Taviot-Gueho, C.; Constantino, V. R. L.; RSC Adv. 2016, 6, 16419.

29. Kong, X.; Jin, L.; Wei, M.; Duan, X.; Appl. Clay Sci. 2010, 49, 324.

30. Ansy, K. M.; Lee, J.-H.; Piao, H.; Choi, G.; Choy, J.-H.; Solid State Sci. 2018, 80, 65.

31. Bastianini, M.; Faffa, C.; Sisani, M.; Petracci, A.; Cosmetics 2018, 5, 51.

32. Costantino, U.; Nocchetti, M.; Sisani, M.; Vivani, R.; Z. Kristallogr. 2009, 224, 273.

33. Lonkar, S. P.; Leuteritz, A.; Heinrich, G.; RSC Adv. 2013, 3, 1495.

34. Coelho, C.; Hennous, M.; Verney, V.; Leroux, F.; RSC Adv. 2012, 2, 5430.

35. Hanwell, M. D.; Curtis, D. E.; Lonie, D. C.; Vandermeersch, T.; Zurek, E.; Hutchison, G. R.; J. Cheminf. 2012, 4, 17.

36. Wang, J.; Wolf, R. M.; Caldwell, J. W.; Kollman, P. A.; Case, D. A.; J. Comput. Chem. 2004, 25, 1157.

37. Frisch, M. J.; Trucks, G. W.; Schlegel, H. B.; Scuseria, G. E.; Robb, M. A.; Cheeseman, J. R.; Scalmani, G.; Barone, V.; Petersson, G. A.; Nakatsuji, H.; Li, X.; Caricato, M.; Marenich, A.; Bloino, J.; Janesko, B. G.; Gomperts, R.; Mennucci, B.; Hratchian, H. P.; Ortiz, J. V.; Izmaylov, A. F.; Sonnenberg, J. L.; Williams-Young, D.; Ding, F.; Lipparini, F.; Egidi, F.; Goings, J.; Peng, B.; Petrone, A.; Henderson, T.; Ranasinghe, D.; Zakrzewski, V. G.; Gao, J.; Rega, N.; Zheng, G.; Liang, W.; Hada, M.; Ehara, M.; Toyota, K.; Fukuda, R.; Hasegawa, J.; Ishida, M.; Nakajima, T.; Honda, Y.; Kitao, O.; Nakai, H.; Vreven, T.; Throssell, K.; Montgomery Jr., J. A.; Peralta, J. E.; Ogliaro, F.; Bearpark, M.; Heyd, J. J.; Brothers, E.; Kudin, K. 
N.; Staroverov, V. N.; Keith, T.; Kobayashi, R.; Normand, J.; Raghavachari, K.; Rendell, A.; Burant, J. C.; Iyengar, S. S.; Tomasi, J.; Cossi, M.; Millam, J. M.; Klene, M.; Adamo, C.; Cammi, R.; Ochterski, J. W.; Martin, R. L.; Morokuma, K.; Farkas, O.; Foresman, J. B.; Fox, D. J.; Gaussian 09, Revision A.01, Gaussian, Inc., Wallingford, CT, 2009.

38. Lee, C.; Yang, W.; Parr, R. G.; Phys. Rev. B 1988, 37, 785.

39. Andersson, M. P.; Uvdal, P.; J. Phys. Chem. A 2005, 109, 2937.

40. Lancaster, F. E.; Lawrence, J. F.; Food Addit. Contam. 1995, $12,9$.

41. Kovary, K.; Louvain, T. S.; Silva, M. C. C.; Albano, F.; Pires, B. B.; Laranja, G. A.; Lage, C. L.; Felzenszwalb, I.; Br. J. Nutr. 2001, 85, 431.

42. Santos, L. F.; Dias, V. M.; Pilla, V.; Andrade, A. A.; Alves, L. P.; Munin, E.; Monteiro, V. S.; Zilio, S. C.; Dyes Pigm. 2014, 110, 72 .

43. Scotter, M. J.; Thorpe, S. A.; Reynolds, S. L.; Wilson, L. A.; Strutt, P. R.; Food Addit. Contam. 1994, 11, 301.

44. Miyata, S.; Clays Clay Miner. 1975, 23, 369.

45. Kohno, Y.; Totsuka, K.; Ikoma, S.; Yoda, K.; Shibata, M.; Matsushima, R.; Tomita, Y.; Maeda, Y.; Kobayashi, K.; J. Colloid Interface Sci. 2009, 337, 117.

46. Kohno, Y.; Asai, S.; Shibata, M.; Fukuhara, C.; Maeda, Y.; Tomita, Y.; Kobayashi, K.; J. Phys. Chem. Solids 2014, 75, 945.

47. Saito, S.; Tasumi, M.; J. Raman Spectrosc. 1983, 14, 310.

48. Oliveira, L. F. C.; Dantas, S. O.; Velozo, E. S.; Santos, P. S.; Ribeiro, M. C. C.; J. Mol. Struct. 1997, 435, 101.

49. Kim, D.; Alam, M. S.; Chung, W.-J.; Koo, S.; ACS Omega 2019 , 4, 10019.

50. Reith, J. F.; Gielen, J. W.; J. Food Sci. 1971, 36, 861.

51. Maia, L. F.; Rimulo, I. M. R.; de Oliveira, V. E.; Arvellos, J. A. F.; Costa, L. A. S.; Edwards, H. G. M.; de Oliveira, L. F. C.; J. Braz. Chem. Soc. 2020, 31, 1370.
52. Kloprogge, J. T.; Hickey, L.; Frost, R. L.; J. Raman Spectrosc. 2004, 35, 967.

53. Xu, Z. P.; Kurniawan, N. D.; Bartlett, P. F.; Lu, G. Q.; Chem.Eur. J. 2007, 13, 2824.

54. Silva, G. S.; Souza, A. G.; Botelho, J. R.; Silva, M. C. D.; Silva, T. M. S.; J. Therm. Anal. Calorim. 2007, 87, 871.

55. Evans, D. G.; Duan, X.; Chem. Commun. 2006, 5, 485.

56. Jondiko, I. J. O.; Pattenden, G.; Phytochemistry 1989, 28, 3159.

57. Ruiz-Anchondo, T.; Flores-Holguín, N.; Glossman-Mitnik, D.; Molecules 2010, 15, 4490.

58. Moss, G. P.; Pure Appl. Chem. 1976, 47, 97.

59. Tirimanna, A. S. L.; Mikrochim. Acta 1981, 2, 11.

60. Rodríguez-deLeón, E.; Bah, M.; Jiménez-Halla, J. O. C.; Bonilla-Cruz, J.; Estévez, M.; Báez, J. E.; Polym. Chem. 2019, 10,6580 .

61. da Costa, C. L. S.; Chaves, M. H.; Quim. Nova 2005, 28, 149.

62. Coates, R. M.; Ley, D. A.; Cavender, P. L.; J. Org. Chem. 1978, $43,4915$.

63. El-Raey, M. A.; Ibrahim, G. E.; Eldahshan, O. A.; J. Pharmacogn. Phytochem. 2013, 2, 245.

64. Ho, H. J.; Shirakawa, H.; Giriwono, P. E.; Ito, A.; Komai, M.; Biosci., Biotechnol., Biochem. 2018, 82, 956.

65. Fliefel, R. M.; Entekhabi, S. A.; Ehrenfeld, M.; Otto, S.; Stem Cells Int. 2019, ID 4351327.

66. Kedare, S. B.; Singh, R. P.; J. Food Sci. Technol. 2011, 48, 412.

67. El-Agamey, A.; Lowe, G. M.; McGarvey, D. J.; Mortensen, A.; Phillip, D. M.; Truscott, T. G.; Young, A. J.; Arch. Biochem. Biophys. 2004, 430, 37.

Submitted: January 15, 2020

Published online: April 8, 2020 